\title{
Novel Type 2 Diabetes Medication Access and Effect of Patient Cost Sharing
}

\author{
Henry J. Henk, PhD; Janice M. S. Lopez, PharmD, MPH; and Brahim K. Bookhart, MBA, MPH
}

\begin{abstract}
BACKGROUND: Although drug formulary restrictions may reduce use of prescription medication and pharmacy costs, the effect of patient cost sharing on medication adherence and health care utilization and cost is unclear.
\end{abstract}

OBJECTIVE: To evaluate the relationship between patient cost sharing for novel type 2 diabetes mellitus (T2DM) medications and medication adherence, persistence, and health care utilization and cost.

METHODS: This retrospective study used medical and pharmacy claims linked to pharmacy benefit plan design data. Patients with T2DM were identified via ICD-9-CM codes (medical claims), outpatient prescription fills (pharmacy claims), and pharmacy benefit design information. Patients with T2DM treated with novel T2DM medications (DPP4 or GLP-1) were enrolled in plans with fixed or coinsurance medication copayment structures and followed for 12-48 months. Endpoints included medication persistence and adherence and total all-cause health care cost. Multivariable regression analysis estimated the effect of benefit design parameters, adjusting for baseline patient characteristics.

RESULTS: The integrated database included 36,475 patients with T2DM. The majority (83.1\%) had fixed copayment plans, and 3-tier plans were common (93.1\%). Higher third-tier copayment was associated with poorer medication adherence and persistence but not total health care cost during follow-up. A \$10 higher third-tier copayment was associated with $11 \%$ greater risk of novel T2DM medication discontinuation and 3\% lower adherence. A comparison of patients with fixed versus coinsurance plans found that fixed plans were associated with higher adjusted persistence and total all-cause health care costs.

CONCLUSIONS: Higher medication copayment amounts were associated with lower patient medication adherence and persistence in T2DM but not total health care costs, as health plan costs decreased while patient outof-pocket costs increased. We observed higher total all-cause health care costs among T2DM patients with a fixed copay (vs. coinsurance) pharmacy benefit. Additional research incorporating plan design information is needed to further examine this finding.

J Manag Care Spec Pharm. 2018;24(9):847-55

Copyright $\odot 2018$, Academy of Managed Care Pharmacy. All rights reserved.

\section{What is already known about this subject}

- Strategies for containment of health care costs are important in type 2 diabetes mellitus (T2DM) management due to its high economic burden and the complex, progressive nature of the disease. The majority of previous studies in T2DM have been restricted by lack of availability of pharmacy benefit plan design data and have relied on observed patient-paid amount rather than copay and deductible information associated with specific drug tiers. Restrictive formulary designs have been shown to reduce medication use and associated pharmacy costs, but there is mixed evidence of their effect on medication adherence and health care utilization and cost.

\section{What this study adds}

Higher medication copayment amounts were associated with lower patient medication adherence and persistence in T2DM. Copayment amount was not associated with total health care costs, since health plan costs decreased while patient out-ofpocket costs increased.

The use of pharmacy benefit plan design data integrated with medical and pharmacy claims data in this study provides a useful framework for future research into the effect of cost sharing.

$\mathrm{F}$ ormulary designs may incorporate mechanisms such as patient cost sharing, prior authorization, step therapy, preferred drug lists, and quantity limits to control prescription costs. Formulary designs, which include these costcontainment mechanisms, have been shown to reduce medication use and associated pharmacy costs, ${ }^{1-5}$ but there is mixed evidence of their effect on medication adherence and persistence and health care utilization and cost. A 2014 systematic review of formulary restriction identified 59 studies that evaluated the effect of patient access to medication on economic outcomes and found that 37\% had neutral, 34\% positive, and 29\% negative association studies; $60 \%$ of included studies $(n=93)$ identified prescription cost sharing as a formulary management strategy. ${ }^{6}$ Thus, medication cost-sharing strategies are frequently used by managed care organizations, and pharmacy benefit designs may include patient prescription cost sharing via fixed copay amounts and coinsurance plans, in which patients pay a percentage of the total medication cost. Fixed copay and coinsurance plans may have different levels (tiers) 
of patient contribution. However, while lowering prescription patient cost sharing in chronic disease care may improve medication adherence, the effect of patient cost sharing on clinical and economic outcomes remains unclear. ${ }^{7}$

Due to the considerable costs associated with type 2 diabetes mellitus (T2DM), evaluations of cost-containment strategies on patient outcomes may have important implications. Total estimated direct treatment costs among persons diagnosed with diabetes in the United States in 2012 was $\$ 176$ billion, with $30 \%$ attributable to antihyperglycemic medications and supplies. ${ }^{8}$ As the number of Americans with diagnosed diabetes in the United States is projected to increase from 11 million (2000) to 29 million by 2050 (165\%), ${ }^{9}$ costs are expected to rise. The goal of diabetes management with antihyperglycemic therapy is to lower blood glucose levels to as near normal as possible, and the American Diabetes Association recommends hemoglobin Alc testing at least twice a year among patients meeting glycemic treatment goals and quarterly among those not meeting goals. ${ }^{10}$ Poor glycemic control in T2DM has been associated with increased risk of complications ${ }^{11,12}$ and higher health care costs. ${ }^{13,14}$ Restrictive formularies may negatively affect T2DM medication adherence. ${ }^{15-19}$ Suboptimal adherence with prescribed T2DM medications has been linked to poorer glycemic control ${ }^{15,20,21}$ and increased health care costs. ${ }^{22-27}$

Formulary management strategies are particularly important in the context of T2DM due to its high economic burden, the need for continuous drug treatment and patient management, and the complex, progressive nature of the disease. Novel T2DM medications (dipeptidyl peptidase-4 inhibitors and incretin mimetics) represent new classes of oral and injectable medications approved to manage T2DM. These medications are associated with relatively high medication costs compared to older T2DM medications, and thus, patients prescribed these medications may be directly affected by higher copayments and higher coinsurance costs. We hypothesized that more "generous" plans are associated with greater adherence, longer persistence, and lower total health care costs in T2DM, using the highest possible copay in the tier (e.g., in 3-tier it may be $\$ 50$ ) and coinsurance as proxies of plan generosity (i.e., measured by cost sharing).

Our primary study objective was to evaluate the relationship between patient cost sharing for novel T2DM medications and patient medication adherence, health care utilization, and health care cost using linked medical and pharmacy claims and pharmacy benefit design data. Specifically, we sought to evaluate the association between the highest-tier pharmacy copayment and health care costs from the payer perspective (defined as the amount paid by the health plan plus patient responsibility), as well as the relationship between a fixed copay versus a coinsurance pharmacy benefit design on patient adherence and health care costs.

\section{Methods}

This was a retrospective, observational cohort study that used Optum's proprietary research database of medical and pharmacy claims linked to plan benefit design and enrollment information for commercially insured members of a large U.S. health plan. Patients who were aged 18 years or older and who had 2 or more medical claims at least 7 days apart for T2DM (International Classification of Diseases, Ninth Revision, Clinical Modification [ICD-9-CM] codes 250.x0 and 250.x) between January 1, 2010, and December 31, 2012, (identification period) were identified for study eligibility. Patients were required to have filled a prescription for a specified novel T2DM medication between January 1, 2010, and December 31, 2012. The following novel T2DM medications were included: alogliptin, sitagliptin, saxagliptin, linagliptin, alogliptin/metformin, sitagliptin/metformin, saxagliptin/metformin, linagliptin/metformin, alogliptin/pioglitazone, sitagliptin/simvastatin, exenatide, and liraglutide. The date of the first qualifying prescription fill during the identification period was designated the study index date, and the specific agent prescribed was considered the index medication.

Patients were further required to be enrolled in either a 2-, 3-, or 4-tiered fixed copayment plan or a coinsurance plan (in which a member pays a percentage of a total prescription cost) and to be continuously enrolled in the health plan for at least 365 days preceding and subsequent to the index date. Study exclusion criteria included the use of the index medication during the study baseline period, which was defined as the 365-day period preceding the index date.

Patients were followed for at least 12 months after the index date. The follow-up period began on the index date and terminated on the earliest date or the following: December 31, 2013; disenrollment from the health plan; or the date of a pharmacy benefit plan change. A pharmacy benefit plan change was defined as either a change in the cost-sharing structure, the multi-tier fixed copayment amount, or the coinsurance amount (percentage).

Study variables included these patient characteristics: patient age (calculated as of the index year), gender, U.S. geographic region (Northeast, Midwest, South, West, other), and health plan funding type (self-insured employers or fully insured employers). Patient baseline health status was assessed using the following methods: the Quan-Charlson Comorbidity score, calculated based on the presence of ICD-9-CM diagnosis codes on medical claims during the study baseline period ${ }^{28,29}$; the Diabetes Complications Severity Index (DCSI), calculated via ICD-9-CM codes during the 12-month baseline period ${ }^{30,31}$; and the total number of unique medications used during the baseline period. Pharmacy benefit design data elements included a fixed copayment structure, in which a member pays a predetermined dollar amount for a prescription fill, or a coinsurance structure, where a member pays a percentage of the 
total cost of a prescription fill. The number of pharmacy benefit tiers was captured for both fixed copayment and coinsurance plans, and both copayment amounts and coinsurance percentages were captured. Maximum copayment amount was defined as the copayment amount of the highest tier; for a 3-tiered plan, this would equal the copayment amount for a third-tier drug, that is, the highest dollar amount that patients could pay for a formulary covered drug on their plan.

Study measures included medication adherence, measured using medication possession ratio (MPR). Adherence was calculated by dividing the sum of the number of days the index medication was supplied for all but the last fill in the observation period by the number of days between the first and the last refill. Patients were required to have at least 2 fills of the index medication. Patients who were perfectly compliant had an MPR of $\geq 1$, while those who were less than fully compliant had an MPR $<1$.

Medication persistence was based on therapy discontinuation, defined as an index medication gap of $\geq 90$ days. Medication persistence was assessed as the number of days from the index date to therapy discontinuation, which was identified as the run-out date based on days supply of the last prescription filled before the qualifying gap in therapy. Health care resource utilization was evaluated as $>1$ emergency department (ED) admission, > 1 inpatient admission, and number of ambulatory visits during study follow-up.

All-cause health care costs were calculated for the combined health plan paid and patient payment responsibility amounts for the study follow-up period. Medical (including ambulatory, ED, inpatient), pharmacy, and other health care costs were included and summed to calculate total all-cause follow-up health care costs.

\section{Statistical Analysis}

Descriptive statistics were calculated as means and standard deviations (SD) for continuous variables and frequencies for categorical variables. Among patients with a 3-tier fixed copay pharmacy benefit, the relationship between maximum third-tier fixed copayment amount and medication adherence was evaluated using ordinary least squares (OLS) regression, controlling for patient demographic and clinical characteristics. Regression coefficients are interpreted as the change in adherence associated with a $\$ 10$ change in maximum copay. Persistence was evaluated using parametric regression survival models based on maximum likelihood estimation to model the time to index medication discontinuation. The probabilities of $>1$ inpatient or ED visit were modeled using logistic regression, and odds ratios and corresponding 95\% confidence intervals (CI) were calculated. The number of ambulatory visits was modeled using a negative binomial regression with a log link to calculate incidence rate ratios and corresponding 95\% CIs. Because health care costs are often skewed, estimated cost measures were

\begin{tabular}{|c|c|c|c|c|c|}
\hline \multirow[b]{2}{*}{$\mathrm{N}=36,475$} & \multirow{2}{*}{$\begin{array}{l}\text { Number } \\
\text { of Tiers }\end{array}$} & \multirow[b]{2}{*}{ n (\%) } & \multicolumn{3}{|c|}{ Copay, \$/Coinsurance, \% } \\
\hline & & & Mean & Median & Range \\
\hline \multirow{4}{*}{$\begin{array}{l}\text { Fixed copay } \\
(\mathrm{n}=30,322)\end{array}$} & 1 & $117 \quad(0.4)$ & 2.86 & 2 & $2-21$ \\
\hline & 2 & $839 \quad(2.8)$ & 23.10 & 20 & $2-65$ \\
\hline & 3 & $28,228(93.1)$ & 54.54 & 50 & $10-125$ \\
\hline & 4 & $1,138 \quad(3.8)$ & 123.69 & 100 & $50-250$ \\
\hline \multirow{4}{*}{$\begin{array}{l}\text { Coinsurance } \\
(n=6,153)\end{array}$} & 1 & $2,707(44.0)$ & 31 & 20 & $10-100$ \\
\hline & 2 & $581 \quad(9.4)$ & 26 & 25 & $20-50$ \\
\hline & 3 & $2,854(46.4)$ & 31 & 25 & $20-65$ \\
\hline & 4 & $11 \quad(0.2)$ & 30 & 30 & $30-30$ \\
\hline
\end{tabular}

aThis table represents patient copayment contribution for all medication, regardless of therapeutic class and is not specific to novel T2DM medications. It is based on plan design information (not claims paid).

T2DM = type 2 diabetes mellitus.

modeled using the Manning and Mullahy formulation ${ }^{32}$ to avoid potential difficulties introduced by transformation and retransformation of the dependent variable ${ }^{33}$; coefficients from a generalized linear model with a log link and gamma distribution are reported as cost ratios (exponentiated coefficients interpreted as the relative change in costs associated with a one-unit change in the variable). To estimate the relationship between a fixed copayment and coinsurance plan, similar analyses to the 3-tier fixed plan analysis for each endpoint were conducted, except that the analysis was limited to patients enrolled in a fixed or coinsurance plan (regardless of tier)

All models included the following independent variables: patient age and gender, insured status (fully insured vs. administrative services only), high deductible medical plan, baseline health care cost (patient responsibility and health plan paid amount), unique medication count, baseline Charlson comorbidity score, and DCSI; models did not include potential interaction effects. In addition, the analysis of 3-tier fixed copayment plan patients included maximum copay amount and maximum copay amount squared, to account for a possible decreasing (or increasing) effect of copay amount as maximum copayment amount increases (i.e., a quadratic relationship between copay amount and the outcome of interest). The analysis of all fixed copayment plan patients versus coinsurance patients included fixed versus coinsurance plan design.

The multivariate regression results were used to estimate predicted values (e.g., average MPR, average cost) for each cohort (adjusted for covariates) using the recycled predictions method,$^{34}$ and corresponding $95 \%$ CIs were estimated by bootstrapping techniques (500 replicates). ${ }^{35,36}$

Review/approval by an institutional review board was not required for this study as it used commercially available deidentified secondary data. 


\begin{tabular}{|c|c|c|c|c|c|}
\hline \multirow[b]{2}{*}{ Variable } & \multirow[b]{2}{*}{$\begin{array}{c}\text { Total } \\
(\mathrm{N}=36,475)\end{array}$} & \multicolumn{4}{|c|}{ Pharmacy Benefit Structure } \\
\hline & & $\begin{array}{c}\text { Coinsurance } \\
(\mathrm{n}=6,153)\end{array}$ & $\begin{array}{c}\text { Fixed Copay } \\
(\mathbf{n}=30,322)\end{array}$ & \multicolumn{2}{|c|}{$\begin{array}{l}\text { 3-Tier Fixed Copay } \\
\quad(\mathrm{n}=28,228)\end{array}$} \\
\hline Age (years), mean (SD) & $54.3 \quad(10.4)$ & $56.7 \quad(11.9)$ & $53.8 \quad(10)$ & 53.6 & $(9.8)$ \\
\hline Male, n (\%) & $20,048 \quad(55.0)$ & $3,324 \quad(54)$ & $16,724 \quad(55.2)$ & 15,518 & $(55.0)$ \\
\hline Length of follow-up (days), mean (SD) & $820.2(298.1)$ & $772.9(293)$ & $829.8(298.2)$ & 830.7 & $(298.6)$ \\
\hline \multicolumn{6}{|l|}{ Funding type, $\mathrm{n}(\%)$} \\
\hline Self-insured employers & 23,850 & $6,087 \quad(98.9)$ & 17,763 & 16,672 & $(59.1)$ \\
\hline Fully insured employers & 12,625 & $(1.1)$ & 12,559 & 11,556 & $(40.9)$ \\
\hline \multicolumn{6}{|c|}{ Comorbidity score (categories $0,1-2,3+$ ), n (\%) } \\
\hline 0 & 22,112 & $3,505 \quad(57)$ & 18,607 & 17,359 & $(61.5)$ \\
\hline $1-2$ & 11,310 & $(32.4)$ & 9,316 & 8,660 & $(30.7)$ \\
\hline $3+$ & 3,053 & $(10.6)$ & 2,399 & 2,209 & $(7.8)$ \\
\hline \multicolumn{6}{|l|}{ DSCI, n (\%) } \\
\hline 0 & 21,116 & $3,336 \quad(54.2)$ & 17,780 & 16,619 & $(58.9)$ \\
\hline $1-2$ & 11,017 & $1,829 \quad(29.7)$ & 9,188 & 8,565 & $(30.3)$ \\
\hline $3+$ & $(11.9)$ & $(16.1)$ & 3,354 & 3,044 & $(10.8)$ \\
\hline Count of unique medications, mean (SD) & $(6.0)$ & $(6.5)$ & $(5.8)$ & 9.6 & $(5.8)$ \\
\hline
\end{tabular}

\section{Results}

\section{Patient and Plan Design Characteristics}

Patients with $\geq 2$ medical claims for T2DM at least 7 days apart, who also had $\geq 1$ prescription claim for a specified novel T2DM medication, met continuous enrollment criteria, and who had all benefit design data were initially selected for study inclusion $(n=40,334)$. Table 1 includes the distribution of pharmacy benefit structure elements among the 36,475 patients enrolled in either a fixed $(n=30,322,83.1 \%)$ or coinsurance $(n=6,153,16.9 \%)$ pharmacy benefit plan; patients with other pharmacy benefit plan designs were excluded $(n=3,859)$. Among fixed copayment plans, the majority of patients had a 3-tier copay plan (93.1\%), while among coinsurance plans, the most common was a 3-tier plan (46.4\%), followed by a 1-tier plan (44.0\%). Median copayment amount among 3-tier fixed plans was $\$ 50$ and $\$ 100$ for 4-tier plans; among 3-tier fixed plans, the copay amount ranged from $\$ 10-\$ 125$. Median copay percentage of medication cost for 3-tier coinsurance plans was 25\% (range 20\%-65\%) and for 1-tier plans was 20\% (range 10\%-100\%). No meaningful changes in pharmacy benefit design elements (fixed vs. coinsurance or number of tiers) were observed between calendar years 2010 and 2012 (data not shown).

Overall, $55.0 \%$ of study patients were male, and mean age was 54.3 years (Table 2). Mean length of study follow-up was 820.2 days $(S D=298.1)$. More than half of the study patients (65.4\%) were on self-insured plans. The majority (59.8\%) of patients resided in the southern United States, followed by $20.7 \%$ in the Midwest, and $10.8 \%$ in the West. The study cohort had few chronic comorbid conditions, as the majority of patients (60.6\%) had a Quan-Charlson comorbidity score of 0 , and more than half of the patients (57.9\%) had a DCSI of 0 , indicating that most patients did not have any complications associated with diabetes that were measured by the index. Mean count of all medications at baseline was $9.8(\mathrm{SD}=6.0)$. Almost all patients with a coinsurance plan were self-insured (98.9\%), whereas $58.6 \%$ of patients with fixed copayment plans were self-insured.

\section{Study Outcomes: Unadjusted Results}

Table 3 includes unadjusted study primary endpoints stratified by plan design (coinsurance, fixed copay, and 3-tier fixed copay) and comparison of health care cost components (inpatient, ambulatory, other medical, and pharmacy) by plan design. Unadjusted mean index medication persistence for the novel T2DM patient cohort with coinsurance was 375 days $(S D=7)$, and for fixed copay, mean persistence was 391 days ( $\mathrm{SD}=3$; Table 3). Mean index medication adherence was 0.72 for fixed and 0.75 for coinsurance plans. Medical costs comprised approximately $64 \%$ of total all-cause health care costs (medical care costs plus pharmacy costs), regardless of pharmacy benefit design. Approximately 57\%-59\% of medical health care costs were attributed to ambulatory costs, while about one third were related to inpatient services (Table 3).

\section{Study Outcomes: Adjusted Results}

The adjusted effect of a higher third-tier pharmacy copayment for patients with a 3-tier fixed copayment plan is illustrated in Table 4. Predicted mean index medication persistence among patients with a $\$ 25$ copay was 327 days (95\% CI=313-340) compared 
TABLE 3 Unadjusted Study of Primary Endpoints by Pharmacy Benefit Structure (Fixed Copay or Coinsurance) in a Cohort with Type 2 Diabetes Mellitus

\begin{tabular}{|c|c|c|c|c|}
\hline \multirow{2}{*}{$\begin{array}{l}\text { Endpoint } \\
\text { Persistence (days), mean (SE) }\end{array}$} & $\begin{array}{c}\text { Coinsurance } \\
(n=6,153)\end{array}$ & $\begin{array}{l}\text { Fixed Copay } \\
(\mathbf{n}=30,322)\end{array}$ & \multicolumn{2}{|c|}{$\begin{array}{l}\text { 3-Tier Fixed Copay } \\
\quad(\mathrm{n}=28,228)\end{array}$} \\
\hline & $375 \quad(7)$ & $391 \quad(3)$ & 388 & (3) \\
\hline Adherence, mean (SD)a & $(0.26)$ & $(0.25)$ & 0.72 & $(0.25)$ \\
\hline \multicolumn{5}{|l|}{ Annual health care resource utilization } \\
\hline$\geq 1$ ED visit, $\mathrm{n}(\%)$ & $(43.8)$ & $(41.12)$ & 11,576 & $(41.01)$ \\
\hline$\geq 1$ Inpatient stay, n (\%) & $(19.58)$ & $(16.92)$ & 4,730 & $(16.76)$ \\
\hline Number of ambulatory visits, mean (SD)b & $(37.66)$ & $(31.59)$ & 31.69 & $(31.74)$ \\
\hline Total all-cause health care cost (\$), mean (SD) & $28,499 \quad(61,322)$ & $28,414 \quad(51,754)$ & 28,706 & $(52,502)$ \\
\hline Medical health care cost (\$), mean (SD) & $18,050 \quad(58,019)$ & $17,998 \quad(48,469)$ & 18,303 & $(49,228)$ \\
\hline Inpatient & $5,749 \quad(30,745)$ & $5,898 \quad(29,800)$ & 6,023 & $(30,543)$ \\
\hline Ambulatory & $10,565 \quad(38,546)$ & $10,347 \quad(25,404)$ & 10,484 & $(25,123)$ \\
\hline All other medical & $1,736 \quad(9,161)$ & $1,753 \quad(8,905)$ & 1,796 & $(9,190)$ \\
\hline Pharmacy health care cost (\$), mean (SD) & $10,449 \quad(12,391)$ & $10,416 \quad(11,800)$ & 10,402 & $(11,829)$ \\
\hline \multicolumn{5}{|c|}{$\begin{array}{l}\text { adherence analysis was conducted among patients with } \geq 2 \text { prescription fills and was calculated by dividing the sum of the number of days the index medication was } \\
\text { supplied for all but the last fill in the observation period, by the number of days between the first and the last refill. The sample sizes for the adherence calculations are as } \\
\text { follows: } 5,484 \text { (coinsurance), } 27,574 \text { (fixed copay), and 25,667 (3-tier fixed copay). } \\
\text { bAmbulatory is physician office and outpatient hospital encounters. } \\
\text { ED=emergency department; } S D=\text { standard deviation; SE= standard error. }\end{array}$} \\
\hline
\end{tabular}

with 279 days ( $95 \% \mathrm{CI}=266-292$ ) for those with a $\$ 100$ copay, and predicted mean adherence (MPR) was $0.76(95 \% \mathrm{CI}=0.75-0.77)$ among patients with a $\$ 25$ copay versus $0.71(95 \% \mathrm{CI}=0.69-0.72)$ among those with a $\$ 100$ copay. Predicted adjusted risk of > 1 ED or inpatient visits appeared to decrease with increasing patient medication copay, as did the predicted mean number of ambulatory visits (Table 4). Although predicted mean total all-cause health care costs were higher $(\$ 37,468,95 \% \mathrm{CI}=33,308-44,260)$ for patients with a $\$ 25$ index medication copay compared with the predicted mean total all-cause health care costs for those with a $\$ 100$ copay $(\$ 29,821,95 \% \mathrm{CI}=\$ 26,348-\$ 35,489)$, the difference was not statistically significant.

Among 3-tier fixed medication copayment plans, a $\$ 10$ higher copayment was associated with an $11 \%$ higher adjusted risk (hazard) of discontinuing the index study medication $(P<0.001$; Table 5). Maximum third-tier copayment amount was found to have a significant negative association with adherence $(P<0.001)$, as a $\$ 10$ difference in third-tier copayment was associated with a 0.03 lower adherence. Higher third-tier copayment was also found to have a significant negative association with number of ambulatory visits (ratio $=0.87$, $P<0.01)$, but not risk of hospitalizations $(\mathrm{OR}=0.99, P=0.85)$ or risk of at least $1 \mathrm{ED}$ visit (OR=0.91, $P=0.05$; data not shown). No statistically significant association was found between maximum third-tier index medication copayment amount and total all-cause health care costs (health plan plus patient paid amounts). While total all-cause health care costs were not associated with cost sharing, we did observe that higher cost sharing was associated with lower health plan and higher patient out-of-pocket costs.
Pharmacy benefit structure design (fixed medication copay vs. coinsurance) was associated with medication persistence, but not adherence. A fixed medication copayment plan was associated with a small but significantly lower risk (4\%) of discontinuing the index study medication as compared to coinsurance plans $(P=0.0078$; data not shown). Compared with coinsurance plans, a fixed pharmacy copay plan (regardless of tier) was associated with higher total all-cause health care costs. A fixed copayment structure was associated with $11 \%$ greater adjusted mean total health care costs compared with coinsurance plans adjusted mean total health care costs.

\section{Discussion}

Among patients with a fixed 3-tier prescription copay plan, a higher third-tier copayment amount was associated with lower T2DM medication persistence and adherence. While we observed an association between maximum third-tier copay and all-cause health care utilization (ED and ambulatory visits) among patients with a 3-tier fixed plan, maximum copayment amount was not found to have a significant association with total all-cause health care costs. Further, a comparison of fixed copayment plans versus coinsurance plans, regardless of copayment tier, found that fixed copayment plans were associated with a lower risk of treatment discontinuation but higher total mean health care costs. The proportion of total unadjusted health care costs attributable to prescription medications were similar for patients with a 3-tier fixed plan (36.2\%) and a coinsurance $(36.7 \%)$ plan.

Our study found that a $\$ 10$ higher third-tier copayment was associated with an $11 \%$ higher risk of discontinuing index 


\begin{tabular}{|c|c|c|c|c|c|c|}
\hline $\begin{array}{l}\text { 3-Tier } \\
\text { Copayment, \$ }\end{array}$ & $\begin{array}{l}\text { Persistence (Days), } \\
\text { Predicted Mean } \\
(95 \% \mathrm{CI})^{\mathrm{a}}\end{array}$ & $\begin{array}{l}\text { Adherence, } \\
\text { Predicted Mean } \\
(95 \% \mathrm{CI})^{\mathrm{a}}\end{array}$ & $\begin{array}{l}\text { Predicted Risk of } \\
\geq 1 \mathrm{ED} \text { visit } \\
\quad(95 \% \mathrm{CI})^{\mathrm{a}}\end{array}$ & $\begin{array}{l}\text { Predicted Risk of } \\
\geq 1 \text { Hospitalization } \\
(95 \% \mathrm{CI})^{\mathrm{a}}\end{array}$ & $\begin{array}{c}\text { Number of } \\
\text { Ambulatory Visits, } \\
\text { Predicted Mean } \\
(95 \% \mathrm{CI})^{\mathrm{a}}\end{array}$ & $\begin{array}{c}\text { Total Health Care Costs, } \$ \\
\text { Predicted Mean } \\
(95 \% \mathrm{CI})^{\mathrm{a}}\end{array}$ \\
\hline 25 & $(313-340)$ & $0.76 \quad(0.75-0.77)$ & $44.4 \quad(41.9-46.9)$ & $17.9 \quad(16.0-19.6)$ & $(38-42)$ & $37,468 \quad(33,308-44,260)$ \\
\hline 50 & $(283-289)$ & $0.72 \quad(0.72-0.72)$ & $41.1 \quad(40.4-41.8)$ & $17.0 \quad(16.5-17.5)$ & $(33-34)$ & $(31,332-39,415)$ \\
\hline 75 & $(267-275)$ & $0.70 \quad(0.70-0.71)$ & $39.6 \quad(38.6-40.6)$ & $15.8 \quad(15.1-16.6)$ & $(30-32)$ & $31,456 \quad(28,706-36,633)$ \\
\hline 100 & $(266-292)$ & $0.71 \quad(0.69-0.72)$ & $39.7 \quad(36.7-42.9)$ & $14.5 \quad(12.5-16.8)$ & $(31-34)$ & $29,821 \quad(26,348-35,489)$ \\
\hline \multicolumn{7}{|c|}{$\begin{array}{l}\text { Note: Values presented are predicted for each cohort (adjusted for covariates) using the recycled predictions method. } 35 \text { All models adjusted for the following covariates: } \\
\text { patient age and gender, fully insured (vs. administrative services only), high deductible medical plan, baseline health care cost (patient responsibility and health plan paid } \\
\text { amount), unique medication count, baseline Charlson comorbidity score, and DCSI. } \\
\text { a95\% CIs were estimated by bootstrapping ( } 500 \text { replicates). } \\
\text { CI= confidence interval; DCSI = Diabetes Complications Severity Index; ED=emergency department. }\end{array}$} \\
\hline
\end{tabular}

novel T2DM medication and a 3\% lower adherence. Consistent with these findings, previous investigations have demonstrated that formulary restrictions are associated with lower T2DM medication adherence and/or persistence. ${ }^{15-19}$ Barron et al. (2008) found mean adherence for oral antihyperglycemic agents that ranged from 0.58 for patients with a copay of $<\$ 10$ compared to 0.52 for patients whose copay was $\$ 20$ or higher, and discontinuation that ranged from $55 \%$ in the lowest copay group $(<10)$ to $67 \%$ among those with a copay of $\$ 30$ or more..$^{15}$ In the current study, mean adherence was considerably higher and ranged from 0.76 for the lowest copay group ( $\$ 25$ copay) to 0.71 for the highest copay group (\$100). Similar findings were reported by Colombi et al. (2008) as adherence to T2DM medications was highest for patients with the lowest copayments, regardless of patient age. ${ }^{17}$ Reynolds et al. (2016) found that higher medication copays were associated with T2DM medication discontinuation. ${ }^{37}$ Zeng et al. (2010) studied a value-based benefit design program that reduced the copayment for diabetes medications by $36.1 \%$ and correspondingly reduced the number of nonadherent patients by $30.0 \%{ }^{19}$ Another study by Zeng et al. (2013) of the effects of coverage gap reform on adherence to T2DM medications found that as patients experienced substantial copayment drops, adherence improved by approximately $0.03 .^{38}$

Fewer studies have investigated the effect of formulary restrictions on health care utilization and cost or patient outcomes. Two recent systematic reviews that evaluated the relationship between formulary restrictions and health care resource utilization and cost across therapeutic areas found mixed results. ${ }^{6,7}$ Among a broad Medicare health maintenance organization population not restricted to chronic medication users, Balkrishnan et al. (2001) found that increased patient prescription copayment was associated with higher health care costs. ${ }^{39}$ Campbell et al. (2011) demonstrated that an increase in prescription copayment $>\$ 5$ (vs. $<\$ 5$ ) was associated with more asthma-related outpatient and ED visits among a population with asthma. ${ }^{40}$ Patients with asthma may be more likely to experience immediacy of symptoms related to poor disease control compared with patients with diabetes. However, consistent with this finding among patients with asthma, Colombi et al. demonstrated that among patients with diabetes aged $<65$ years, total health care costs were $22 \%$ lower for patients with low $(<\$ 10)$ copays compared with high copays $(>\$ 10)$, resulting in an average savings of $\$ 3,116$ per patient per year. ${ }^{17}$ This difference in all-cause health care costs was observed despite significantly higher pharmacy costs among patients with low copays.

In contrast, Brixner et al. (2007) found no effect of pharmacy benefit design change (defined as a second- or third-tier copayment increase $>\$ 5$ or a change from a fixed copayment to coinsurance) on overall health care costs within 1 year across 5 chronic conditions, including diabetes. ${ }^{41}$ Similarly, Fairman et al. (2003) found similar rates of inpatient, ED, and outpatient utilization among chronic medication users with a 3-tier (vs. 2-tier) medication formulary structure. ${ }^{42}$ While our results suggest that higher maximum third-tier copay was associated with decreased health care utilization (ED and ambulatory visits), we did not observe a significant relationship between third-tier copayment and health care cost during our 1- to 3-year follow-up period.

Since diabetes is a chronic disease that usually progresses to complications slowly, the effects of medication utilization on medical resources use may take time to manifest. Thus, as others have suggested, ${ }^{41} 1$ year of follow-up may not be sufficient to evaluate the effect of medication adherence on overall health care costs. This may be particularly true for diabetes, as the potential effect of reduced medication adherence on glycemic control and its subsequent effect on the development of diabetes complications may not be fully measurable in the short term. Furthermore, as indicated by DCSI, the majority of the study's patients had no evidence of diabetic complications, indicating a less severe cohort of patients with diabetes. 


\section{TABLE 5 Multivariate Results for Persistence, Adherence, and Health Care Cost Among Fixed 3-Tier Plans}

\begin{tabular}{|c|c|c|c|c|c|c|}
\hline \multirow{2}{*}{$\begin{array}{l}\text { Variables } \\
\text { Maximum copay (\$10 increments) }\end{array}$} & \multicolumn{2}{|c|}{$\begin{array}{l}\text { Persistence }^{\mathrm{a}} \\
\text { HR (P Value) }\end{array}$} & \multicolumn{2}{|c|}{$\begin{array}{l}\text { Adherence }^{b} \\
\text { OLS (P Value) }\end{array}$} & \multicolumn{2}{|c|}{$\begin{array}{c}\text { Health Care Cost }{ }^{\mathrm{c}} \\
\text { GLM (P Value })\end{array}$} \\
\hline & 1.11 & $(0.0000)$ & -0.03 & $(0.0000)$ & 0.95 & $(0.1945)$ \\
\hline Maximum copay, squared & 0.99 & $(0.0012)$ & 0.00 & $(0.0007)$ & 1.00 & $(0.5805)$ \\
\hline Age (years) & 0.99 & $(0.0000)$ & 0.01 & $(0.0000)$ & 1.01 & $(0.0000)$ \\
\hline Male & 0.91 & $(0.0000)$ & 0.04 & $(0.0000)$ & 1.03 & $(0.1507)$ \\
\hline Fully insured (reference: self-insured) & 1.01 & $(0.6870)$ & 0.00 & $(0.2796)$ & 0.93 & $(0.0011)$ \\
\hline High deductible medical plan & 1.11 & $(0.0000)$ & 0.00 & $(0.4221)$ & 0.97 & $(0.4325)$ \\
\hline Baseline patient contribution, \$ & 1.00 & $(0.2614)$ & 0.00 & $(0.0000)$ & 1.00 & $(0.0000)$ \\
\hline Baseline payer, $\$$ & 1.00 & $(0.0001)$ & 0.00 & $(0.3395)$ & 1.00 & $(0.0000)$ \\
\hline Unique prescription medications & 1.00 & $(0.0000)$ & 0.00 & $(0.0010)$ & 1.04 & $(0.0000)$ \\
\hline Charlson comorbidity score & -1.01 & $(0.0302)$ & -0.00 & $(0.3054)$ & 1.08 & $(0.0000)$ \\
\hline Baseline DCSI & 1.03 & $(0.0000)$ & -0.01 & $(0.0000)$ & 1.05 & $(0.0000)$ \\
\hline Constant & 0.00 & $(0.0000)$ & 0.49 & $(0.0000)$ & 11619.02 & $(0.0000)$ \\
\hline
\end{tabular}

Most literature reviews conducted to date have not been condition-specific and have synthesized literature for both symptomatic (e.g., asthma) and relatively asymptomatic (e.g., hypertension) chronic conditions, and the effect of copayment changes may be different based on the underlying chronic disease. Our study, however, did find that a fixed prescription copay plan was associated with higher total health care costs during a mean of approximately 2.3 years of follow-up compared to a coinsurance plan suggesting an effect of pharmacy benefit design on costs. ${ }^{41}$ However, due to the chronic progressive nature of diabetes, it is plausible that these increased short-term costs may be associated with improved patient care and glycemic control, and any associated longer-term cost consequences of this may not be evident in the short term, that is, during our study's follow-up period. As relatively few studies have investigated this relationship, additional research is warranted to understand the relationship between formulary restrictions and overall health care utilization and cost.

\section{Limitations}

This retrospective study of a geographically diverse commercial population enabled the assessment of usual care in a large cohort of patients with T2DM. Furthermore, our study used pharmacy benefit design information linked to medical and prescription claims. This allowed the evaluation of maximum patient copay amount without relying on the use of administrative claims as a proxy to this information and also facilitated the evaluation of fixed-versus-coinsurance plan designs' associations with patient outcomes.

Despite these strengths, it is important to consider our study's findings in the context of some study limitations. Only the effect of pharmacy benefit design information was evaluated, and medical plan benefit design may also be associated with outcomes, particularly health care utilization and cost. Patients with a pharmacy benefit with lower patient cost sharing may be likely to have a similarly generous medical plan benefit, and we did not distinguish between these factors. Patient health status may have been correlated with plan design, as it is plausible that patients who may have selected a coinsurance plan may have elected to take on greater financial risk due to perceived health status, which could have led to selection bias in our study.

It is also important to consider that most coinsurance plans in this study were associated with self-insured employers; these employers may differ qualitatively from fully ensured employers, but we were unable to examine other employer characteristics beyond type of funding, which was included in multivariate models for adjustment of outcome variables.

Patient plan benefit design may also correlate with unmeasured patient characteristics and other social determinants of health, such as education level and socioeconomic status; it is also possible that these unmeasured characteristics are associated with some outcome variables of interest, such as medication adherence.

While our study did control for patient age, diabetes severity (DCSI), and Quan-Charlson comorbidity score, information regarding patient duration of disease (diabetes) was not available for analysis, and longer duration of disease may be associated with higher medical care costs.

Finally, since a cross-sectional, observational study design was used, we should be cognizant that correlations between benefit design and measured medication adherence and health care utilization do not imply that one causes the other. 


\section{Conclusions}

Pharmacy benefit designs with higher copayment amounts may have an effect on patient adherence and persistence to novel medications used to treat T2DM. While we observed higher total all-cause health care costs among patients with a fixed copay pharmacy benefit compared with a coinsurance plan, we observed no difference in all-cause health care costs across levels of copayment among those with a fixed copay benefit. Additional research incorporating plan design information over a longer time period is needed to further examine this finding.

Our study is unique in its use of specific plan design information to examine associations between formulary design and provides important precedent in the use of this type of information to subsequent research in this area. Although there is some research examining the relationship between patient cost sharing on health care resource utilization and associated costs in T2DM, few studies have addressed clinical outcomes (e.g., glycemic control, development of complications, etc.) in T2DM, and additional research is warranted for both clinical and economic endpoints.

\section{Authors}

HENRY J. HENK, PhD, Optum, Eden Prairie, Minnesota; JANICE M. S. LOPEZ, PharmD, MPH, Janssen Scientific Affairs, Titusville, New Jersey; and BRAHIM K. BOOKHART, MBA, MPH, Janssen Scientific Affairs, Raritan, New Jersey.

AUTHOR CORRESPONDENCE: Henry J. Henk, PhD, Optum Labs, 11000 Optum Cir., Eden Prairie, MN 55344. Tel.: 952.205.7708;

E-mail: henry.henk@optum.com.
4. Lu CY, Ross-Degnan D, Soumerai SB, Pearson SA. Interventions designed to improve the quality and efficiency of medication use in managed care: a critical review of the literature-2001-2007. BMC Health Serv Res. 2008;8:75.

5. Shoemaker SJ, Pozniak A, Subramanian R, Mauch D. Effect of 6 managed care pharmacy tools: a review of the literature. J Manag Care Pharm. 2010;16(6 Suppl):S3-20. Available at: https://www.jmcp.org/doi/ abs/10.18553/jmcp.2010.16.S6-A.1.

6. Happe LE, Clark D, Holliday E, Young T. A systematic literature review assessing the directional impact of managed care formulary restrictions on medication adherence, clinical outcomes, economic outcomes, and health care resource utilization. J Manag Care Spec Pharm. 2014;20(7):677-84. Available at: https://www.jmcp.org/doi/abs/10.18553/jmcp.2014.20.7.677.

7. Mann BS, Barnieh L, Tang K, et al. Association between drug insurance cost sharing strategies and outcomes in patients with chronic diseases: a systematic review. PLoS One. 2014;9(3):e89168.

8. American Diabetes Association. Economic costs of diabetes in the U.S. in 2012. Diabetes Care. 2013;36(4):1033-46.

9. Boyle JP, Honeycutt AA, Narayan KM, et al. Projection of diabetes burden through 2050: impact of changing demography and disease prevalence in the U.S. Diabetes Care. 2001;24(11):1936-40.

10. American Diabetes Association. Standards of medical care in diabetes-2016. Diabetes Care. 2017;40(Suppl 1):S1-S135.

11. Effect of intensive blood-glucose control with metformin on complications in overweight patients with type 2 diabetes (UKPDS 34). UK Prospective Diabetes Study (UKPDS) Group. Lancet. 1998;352(9131):854-65.

12. Intensive blood-glucose control with sulphonylureas or insulin compared with conventional treatment and risk of complications in patients with type 2 diabetes (UKPDS 33). UK Prospective Diabetes Study (UKPDS) Group. Lancet. 1998;352(9131):837-53

13. Wagner EH, Sandhu N, Newton KM, McCulloch DK, Ramsey SD, Grothaus LC. Effect of improved glycemic control on health care costs and utilization. JAMA. 2001;285:182-9.

14. Gilmer TP, O'Connor PJ, Manning WG, Rush WA. The cost to health plans of poor glycemic control. Diabetes Care. 1997;20:1847-53.

15. Barron J, Wahl P, Fisher M, Plauschinat C. Effect of prescription copayments on adherence and treatment failure with oral antidiabetic medications. P T. 2008;33(9):532-53.

16. Chernew M, Gibson TB. Cost sharing and HEDIS performance. Med Care Res Rev. 2008;65(6):713-28

17. Colombi AM, Yu-Isenberg K, Priest J. The effects of health plan copayments on adherence to oral diabetes medication and health resource utilization. J Occup Environ Med. 2008;50(5):535-41.

18. Gu Q, Zeng F, Patel BV, Tripoli LC. Part D coverage gap and adherence to diabetes medications. Am J Manag Care. 2010;16(12):911-18

19. Zeng F, An JJ, Scully R, Barrington C, Patel BV, Nichol MB. The impact of value-based benefit design on adherence to diabetes medications: a propensity score-weighted difference in difference evaluation. Value Health. 2010;13(6):846-52

20. Rozenfeld Y, Hunt JS, Plauschinat C, Wong KS. Oral antidiabetic medication adherence and glycemic control in managed care. Am J Manag Care. 2008;14(2):71-5

21. Ho PM, Rumsfeld JS, Masoudi FA, et al. Effect of medication nonadherence on hospitalization and mortality among patients with diabetes mellitus. Arch Intern Med. 2006;166(17):1836-41.

22. Chandran A, Bonafede MK, Nigam S, Saltiel-Berzin R, Hirsch LJ, Lahue BJ. Adherence to insulin pen therapy is associated with reduction in healthcare costs among patients with type 2 diabetes mellitus. Am Health Drug Benefits. 2015;8(3):148-58.

23. Egede LE, Gebregziabher M, Dismuke CE, et al. Medication nonadherence in diabetes: longitudinal effects on costs and potential cost savings from improvement. Diabetes Care. 2012;35(12):2533-39. 
24. Shenolikar RA, Balkrishnan R, Camacho FT, Whitmire JT, Anderson RT. Comparison of medication adherence and associated health care costs after introduction of pioglitazone treatment in African Americans versus all other races in patients with type 2 diabetes mellitus: a retrospective data analysis Clin Ther. 2006;28(8):1199-07.

25. Balkrishnan R, Rajagopalan R, Camacho FT, Huston SA, Murray FT, Anderson RT. Predictors of medication adherence and associated health care costs in an older population with type 2 diabetes mellitus: a longitudinal cohort study. Clin Ther. 2003;25(11):2958-71.

26. Sokol MC, McGuigan KA, Verbrugge RR, Epstein RS. Impact of medication adherence on hospitalization risk and healthcare cost. Med Care. 2005;43(6):521-30.

27. Roebuck MC, Liberman JN, Gemmill-Toyama M, Brennan TA. Medication adherence leads to lower health care use and costs despite increased drug spending. Health Aff (Millwood). 2011;30(1):91-9.

28. Bayliss EA, Ellis JL, Shoup JA, Zeng C, McQuillan DB, Steiner JF. Association of patient-centered outcomes with patient-reported and ICD-9based morbidity measures. Ann Fam Med. 2012;10(2):126-33.

29. Quan H, Li B, Couris CM, et al. Updating and validating the Charlson comorbidity index and score for risk adjustment in hospital discharge abstracts using data from 6 countries. Am J Epidemiol. 2011;173(6):676-82.

30. Chang HY, Weiner JP, Richards TM, Bleich SN, Segal JB. Predicting costs with diabetes complications severity index in claims data. Am J Manag Care. 2012;18(4):213-19.

31. Young BA, Lin E, Von Korff M, et al. Diabetes complications severity index and risk of mortality, hospitalization, and healthcare utilization. Am J Manag Care. 2008;14(1):15-23.

32. Manning WG, Mullahy J. Estimating log models: to transform or not to transform? J Health Econ. 2001;20(4):461-94.
33. Manning WG. The logged dependent variable, heteroscedasticity, and the retransformation problem. J Health Econ. 1998;17(3):283-95.

34. Basu A, Rathouz PJ. Estimating marginal and incremental effects on health outcomes using flexible link and variance function models. Biostatistics. 2005;6(1):93-109.

35. Manning WG, Fryback DG, Weinstein MC. Reflecting uncertainty in cost-effectiveness analysis. In: Gold MR, Siegel JE, Russell LB, Weinstein MC, eds. Cost-Effectiveness in Health and Medicine. New York: Oxford University Press; 1996:247-75.

36. Efron B, Tibshirani R. An Introduction to the Bootstrap. New York: Chapman \& Hall; 1993.

37. Reynolds K, An J, Wu J, et al. Treatment discontinuation of oral hypoglycemic agents and healthcare utilization among patients with diabetes. J Diabetes Complications. 2016;30(8):1443-51.

38. Zeng F, Patel BV, Brunetti L. Effects of coverage gap reform on adherence to diabetes medications. Am J Manag Care. 2013;19(4):308-16.

39. Balkrishnan R, Byerly WG, Camacho FT, Shrestha A, Anderson RT. Effect of prescription benefit changes on medical care utilization in a Medicare HMO population. Am J Manag Care. 2001;7(11):1093-00.

40. Campbell JD, Allen-Ramey F, Sajjan SG, Maiese EM, Sullivan SD. Increasing pharmaceutical copayments: impact on asthma medication utilization and outcomes. Am J Manag Care. 2011;17(10):703-10.

41. Brixner DI, Joish VN, Odera GM, Avey SG, Hanson DM, Cannon HE. Effects of benefit design change across 5 disease states. Am J Manag Care. 2007;13(6 Pt 2):370-76.

42. Fairman KA, Motheral BR, Henderson RR. Retrospective, long-term follow-up study of the effect of a three-tier prescription drug copayment system on pharmaceutical and other medical utilization and costs. Clin Ther. 2003;25(12):3147-61. 